\title{
Abundance of surfactant-like particles reflects mucosal integrity in patients with peptic ulcer disease
}

\author{
R Eliakim, D H Alpers, R Oren, A Fich, K DeSchryver-Kecskemeti
}

\begin{abstract}
Background-Surfactant-like particles, normal products of the human enterocyte, are released into the lumen and secreted into blood.

Aims-To assess their role as markers for mucosal functional integrity, this study examined their content in biopsy specimens and serum of patients with duodenal ulcer disease, compared with non-diseased control subjects.

Patients-Endoscopic biopsy specimens were taken 1-2 cm from areas of active inflammation or ulcer (peptic ulcer patients) or just beyond the duodenal bulb (normals) in 35 consecutive subjects.

Methods-After staining for phospholipid, extracellular and intracellular particles were counted on transmission electron micrographs of coded specimens. Serum was obtained from 24 patients, and densitometry of the $59 \mathrm{kDa}$ band detected on western blot by antiserum against human jejunal particle was measured.

Results-Normal duodenum $(n=15)$ contained more particles $(44(4 \cdot 7))$ particles/ block, mean (SD) than active duodenal ulcer ( $n=13,17(3.9))$ or gastritis/duodenitis patients $(n=4,9(2 \cdot 7))$. Three patients examined after healing of duodenal ulcers showed abundant particles $(\mathrm{n}=3,67(2 \cdot 2))$. Similarly, the $59 \mathrm{kDa}$ band was decreased in serum of patients with active peptic ulcer disease $(n=11,0.25$ $(0 \cdot 04)$ absorbance units) compared with normal patients $(n=10,0.40(0.03))$ or healed ulcers $(n=3,0.62(0.04))$. There was good correlation between morphological mucosal particle abundance and particle protein content of serum assayed from the same patients $(r=0.831)$. These changes were independent of Helicobacter pylori status.
\end{abstract}

Conclusion-The mucosal and serum content of surfactant-like particles may reflect general mucosal integrity of the enterocytes from which they are derived. (Gut 1996; 39: 353-359)

Keywords: peptic ulcer disease, surfactant-like particle.

Pulmonary surfactant is a phospholipid-rich structure that carries specific surfactant proteins, together creating the unique properties of that structure. ${ }^{1}$ The presence of a lipid layer with a phospholipid composition and surface tension lowering activity similar to that of pulmonary surfactant, and which also contains some of the surfactant proteins, has been described in the apical lining of gastrointestinal organs at various levels, in a number of mammals, including humans, dogs, and rats. ${ }^{2-5}$ Phospholipid-rich structures have been observed morphologically within rat gastric and intestinal epithelial cells, on the apical surface beneath the mucus layer, and within paracellular spaces. ${ }^{6-8}$ They have also been found in many other extrapulmonary tissues, such as kidney, synovium, pericardium, ${ }^{9}$ and neurons. ${ }^{10}$ In the intestine these structures, called surfactant-like particles (SLP) have an internal periodicity of $4 \mathrm{~nm}$, similar to the lamellar structures of pulmonary surfactant, with interlamellar spacing of 4-5 nm. ${ }^{11}$ The SLP intracellularly also have solid centres $^{3}$ similar to lamellar bodies in type 2 pneumocytes. ${ }^{11}$ In the rat and human small intestine also these particles have been isolated and found to differ from the apical brush border membranes, having an enzyme component and buoyant density that is distinct. ${ }^{45}$ In addition, the purified rat small intestinal SLP has been shown to have surfactant activity ${ }^{3}$ and to contain at least three of the pulmonary surfactant proteins, SP-B and SP-D, ${ }^{4}$ and SP-A. ${ }^{12}$ Thus, SLPs are not artefacts of tissue preservation, but appear to be organ specific biological structures with as yet incompletely defined functions. These phospholipid structures have been proposed to play a protective part in the gastric mucosa, ${ }^{13}$ perhaps by creating a zone of hydrophobicity at the cell surface. ${ }^{13-17}$

If SLPs perform a protective role in the duodenum (either structurally or functionally), they presumably would not interfere with absorptive function. In fact, in the small intestine SLPs seem to play a part in fat absorption. ${ }^{18}$ SLPs from the small intestine are secreted into the blood and onto the apical surface of the enterocyte. ${ }^{19}$ Thus, independent of their biological functions, these proteins also may provide organ specific markers to monitor the production and secretion of these structures into the blood. These markers might be especially useful in studying human disease, because of the inconvenience of obtaining intestinal mucosal samples at frequent intervals.

Peptic ulcer disease provides a model in which tissue can be readily biopsied to discover if the tissue and serum contents of phospholipid or SLP proteins correlated with
St Louis,

USA.

Accepted for publication 9 May 1996 
the integrity of the tissue. At least one study reported decreased total phospholipid concentrations in gastric mucosa of patients with gastritis and gastric ulcer, when compared with controls, ${ }^{20}$ but another study found no difference in total phospholipid concentration of gastric mucosa between controls and patients with duodenal ulcer. ${ }^{21}$ However, there may not be a linear relation between total phospholipid content of endoscopic biopsy specimens and the concentration of SLP found by microscopy. ${ }^{22}$ The aim of this study was to compare the content of SLPs in the duodenum and serum of normal patients to those with confirmed duodenal ulcer disease.

\section{Methods}

\section{Human subjects}

The study population consisted of 35 consecutive patients who underwent upper gastrointestinal endoscopy at Hadassah Mount Scopus Hospital (Jerusalem). Indications for endoscopy included epigastric pain, nausea, vomiting, or heartburn. None of the patients was taking non-steroidal anti-inflammatory drugs or antibiotics, or was an alcohol misuser. Five patients were taking $\mathrm{H}_{2}$ receptor antagonists, two of whom were found to have active duodenal ulcer and three had healed ulcers. Patients were sedated with $2 \mathrm{mg}$ of midazolam intravenously. Gastritis or duodenitis was defined as either haemorrhages, red streaks, or erosions; healed duodenal ulcer was identified by the presence of an ulcer scar. The other two groups of patients were those with normal appearing mucosa, and those with active duodenal ulcer. Two pinch biopsy specimens were taken from each subject from a noninflamed area in the duodenum, $1-2 \mathrm{~cm}$ from the area of endoscopic inflammation or ulcer, or immediately beyond the duodenal bulb in patients with normal mucosa. All biopsy specimens were fixed for SLP analysis by transmission electron microscopy. After the first 11 patients were entered into the study, the protocol was modified because of the availability of antiserum raised against human small intestinal SLP. ${ }^{5}$ Thus, from the remaining subjects $(n=24)$ biopsy samples were also fixed for light microscopic immunocytochemistry, and the patients had $5 \mathrm{ml}$ of blood drawn for western blot analysis at the time of endoscopy. Unfortunately, some of the specimens could not be processed for microscopy because of damage during transport. The serum samples obtained from all patients in the second half of the study ( 24 of 35 total patients) were tested for antibodies against Helicobacter pylori using an ELISA. ${ }^{23}$ The study was approved by the local ethics committee and written informed consent was obtained from all subjects.

\section{Tissue preparation for routine microscopy}

In 19 cases that could be evaluated, both control and patient biopsy specimens were fixed in $10 \%$ buffered formalin and embedded routinely in paraffin wax. Five micron thick sections, stained with haematoxylin and eosin, were used for evaluation of inflammatory activity. All samples were identified by code numbers, with the code not broken until the study was completed. The inflammation was graded qualitatively on a scale of 0-4, evaluating relative numbers of inflammatory cells present, the predominant pattern (polymorphs versus lymphoplasmacytic infiltrates), and attendant epithelial changes such as regenerative basophilia and loss of polarity. The biopsy specimens were then divided into groups of low grade inflammation $(n=16)$ or high grade inflammation $(n=3)$, depending on the presence or absence of ongoing epithelial destruction.

Tissue preparation for immunohistochemical study The standard avidin-biotin-peroxidase complex method was used. ${ }^{4}$ Briefly, deparaffinised sections were treated with $0.5 \% \quad \mathrm{H}_{2} \mathrm{O}_{2}$ in methanol for 10 minutes, followed by blocking antibodies and incubation at $37^{\circ} \mathrm{C}$ for one hour with the antiserum against human small bowel SLP. ${ }^{5}$ After incubation with biotinylated goat antirabbit immunoglobulin $G$ and Vectastain ABC (Vector Labs, Burlingame, CA) for 30 minutes at $37^{\circ} \mathrm{C}$, the immunohistochemical reaction product was revealed using diaminobenzidine tetrahydrochloride (Sigma Chemical Co, St Louis, MO) and $\mathrm{H}_{2} \mathrm{O}_{2}$ in phosphate buffered saline. Between each application of antiserum, the sections were thoroughly rinsed with phosphate buffered saline. In the control sections, the primary antibody was replaced by normal rabbit serum.

\section{Antiserum}

The antiserum against human SLP was adsorbed for one hour at $37^{\circ} \mathrm{C}$ with purified human small intestinal microvillous membranes to remove reactivity against alkaline phosphatase, and the antiserum was used for immunocytochemistry at a dilution of 1:500, and for western blotting at a dilution of 1:2000. The antiserum identified five major proteins with apparent molecular weights of 118,97 , 62,52 , and $42 \mathrm{kDa}$. Although intestinal alkaline phosphatase migrates at near $(65 \mathrm{kDa})$ the most reactive $62 \mathrm{kDa}$ band, the adsorbed antiserum did not identify any brush border proteins (including alkaline phosphatase). ${ }^{5}$ In the gastric mucosa the antiserum identified weakly only one protein, and it was of a different size than those in the SLP.

\section{Ultrastructural studies}

Tissues from all 35 patients were fixed in 1\% glutaraldehyde (Polyscience, Warrington, PA) and $4 \%$ paraformaldehyde with $0.1 \mathrm{mM} \mathrm{CaCl}_{2}$ in $0.1 \mathrm{M}$ phosphate buffer, $\mathrm{pH} 7 \cdot 4$, and also containing tannic acid $0 \cdot 2 \%$ to improve identification of phospholipid-rich membranes. ${ }^{3625}$ Similar findings were seen using $0.67 \%$ tannic acid. Tissues were kept at $4^{\circ} \mathrm{C}$ for two to four hours in fixative, washed extensively with $0 \cdot 1 \mathrm{M}$ phosphate buffer and 
$0.1 \mathrm{mM} \mathrm{CaCl}$, and placed in the same buffer containing $3.5 \%$ sucrose in which they were stored until ready to examine. Tissue blocks were exposed to $1 \% \mathrm{OsO}_{4}$ in phosphate buffer for one hour at room temperature and rinsed free of phosphate with $50 \mathrm{mM}$ maleate buffer. Tissue was stained with $2 \%$ uranyl acetate, dehydrated in graded alcohol, and embedded in Spurr's resin. Ultrathin sections were cut on a Porter-Blum MT-2B and viewed at $40 \mathrm{kV}$ on a Phillips CM10 microscope after lead citrate staining. SLP were counted on electron micrographs at 17000 magnification, according to standard principles of morphometry. ${ }^{26}$ At least six blocks were examined in each case and SLP were identified by the lamellar appearance of electron dense membrane, either outside or within the cell. All samples were evaluated without knowledge of the clinical status of the patients. In some experiments semi-quantitative comparison of SLP number was performed by counting the cells in at least five blocks, and the content of SLP was quantified from $0-4$. In this scale $1=0-1$ particle found after a lengthy search, $2=$ particles easily found associated with each cell, 3=abundant intra or extracellular particles, and 4=abundant intra and extracellular particles associated with each cell. The agreement between the quantitative and semiquantitative analysis was very good, with a regression coefficient of 0.908 when paired observations on the same samples were compared by least squares analysis.

\section{Western blots}

Antiserum against human jejunal SLP $^{5}$ was adsorbed with intestinal brush borders $(1 \mathrm{mg}$ protein $/ \mathrm{ml}$ ) at room temperature for one hour, so that the adsorbed antibody did not recognise intestinal alkaline phosphatase on western blots using the sensitive ECL system (Amersham, Arlington Heights, IL). All serum samples were diluted $1: 100$, and $1 \mu \mathrm{l}$ of each diluted sample was applied to a $10 \%$ sodium dodecyl sulphate-acrylamide gel under denaturing conditions. The proteins were transferred using Immobilon-P membranes (Millipore, Bedford, MA), blocked overnight at $4^{\circ} \mathrm{C}$ with $5 \%$ non-fat dry milk, $0 \cdot 1 \%$ TWEEN 20 in TRIS buffered saline, pH 7.8. After washing with TWEEN/TRIS/saline buffer, membranes were incubated with antiserum against human SLP (1:2000 dilution) for one hour at room temperature. Second antibody (antirabbit horseradish peroxidase linked donkey antibody (Amersham, Arlington Heights, IL)) was used at 1:5000 dilution for one hour, also at room temperature. Purified human small intestinal SLP served as a positive control, and rat serum as a negative control. All serum samples were electrophoresed and developed by fluorography at the same time, to permit meaningful quantitative comparisons. Samples were tested in duplicate. All major protein bands of the particle were identified in human sera, although their apparent molecular weight was slightly different than in the purified SLP. The most prominent band migrated at $59 \mathrm{kDa}$ rather than $62 \mathrm{kDa}$, perhaps due to the high concentration of protein in serum, as compared with isolated SLP. Purified SLP added to serum showed a major band at $59 \mathrm{kDa}$ rather than at $62 \mathrm{kDa}$. The $59 \mathrm{kDa}$ band was chosen for quantitation by densitometry, using an LKB Ultroscan XL densitometer. To ensure internal control for the western blots, in each gel normal and duodenal ulcer samples were included. The reproducibility of the western blot quantitation was excellent, with a coefficient of variation of $2-8 \%$.

\section{Statistics}

The means of the direct counts or the microscopic scores for SLP content from each of the three groups with peptic ulcer disease were compared with the normal group by the two tailed Student's $t$ test of samples with unequal variance (Microsoft Excel). Least squares regression analysis was used to compare mucosal SLP count with serum SLP protein content (or mucosal SLP count to mucosal SLP score) in those patients for whom both parameters were available.

\section{Results}

Table I shows the demographics of the four endoscopic groups of subjects. There was no difference in the mean age of the patients, and none had prior gastrointestinal surgery. Eleven of 13 patients with active duodenal ulcer were not receiving treatment at the time of the biopsy. None of the patients was taking non-steroidal anti-inflammatory drugs or antibiotics. Nearly $50 \%$ of the patients in the control and active ulcer groups were cigarette smokers (1-10/day).

Immunohistochemical staining at the light microscopic level (Fig 1B) showed staining for SLP within enterocytes at the tip of the villi, but not goblet cells (compare Fig 1B with Fig 1A). The cross sections also demonstrated strong specific staining in the intervillous spaces adjacent to the apical membrane, but the microvillous membrane did not stain (Fig 1B). The reticulated pattern in the intervillous space was not detected in the sections using non-immune serum (Fig 1A). This reticulated pattern appeared to correspond in distribution to that of the electron dense lamellar bodies seen in the rat intestinal lumen ${ }^{3}$ and in human tissue (Fig 2), - closely approximated to the apical microvillous membrane

On electron microscopy, particles were found both outside and inside the cell (Figs 2 and 3) and prominently within the paracellular space (see arrows, Fig 3A). The intracellular and apical SLP are densely stained and rounded, similar to lamellar bodies within type II pneumocytes ${ }^{11}$ and to SLP within rat small intestine. ${ }^{3}$ These intracellular structures are not usually considered to be artefacts of preparation. ${ }^{27}$ Lamellated membranes in the lumen were adjacent to the apical membrane of duodenal enterocytes near the tip of the 
TABLE I Epidemiological data

\begin{tabular}{|c|c|c|c|c|}
\hline Variable & Normal controls & $\begin{array}{l}\text { Active duodenal } \\
\text { ulcer }\end{array}$ & $\begin{array}{l}\text { Healed duodenal } \\
\text { ulcer }\end{array}$ & $\begin{array}{l}\text { Gastritis/ } \\
\text { duodenitis }\end{array}$ \\
\hline $\begin{array}{l}\text { Sample number } \\
\text { Male/female } \\
\text { Mean age (range) } \\
\text { Previous operation }\end{array}$ & $\begin{array}{l}15 \\
8 / 7 \\
45 \cdot 6(30-71) \\
\text { none }\end{array}$ & $\begin{array}{l}13 \\
9 / 4 \\
45 \cdot 9(26-81) \\
\text { none }\end{array}$ & $\begin{array}{l}3 \\
2 / 1 \\
44 \cdot 6(36-54) \\
\text { none }\end{array}$ & $\begin{array}{l}4 \\
2 / 2 \\
48 \cdot 5(23-68) \\
\text { none }\end{array}$ \\
\hline
\end{tabular}

villus, and were present in various stages of unravelling (Figs 2 and 3C). Although such extracellular oligolamellar vesicles can on occasion represent an artefact, ${ }^{27}$ they have been consistently seen in rat intestine using a variety of fixation times and conditions. ${ }^{36}$ Moreover, in the rat after fat feeding the intra and extracellular content of these structures increased and correlated with an ELISA
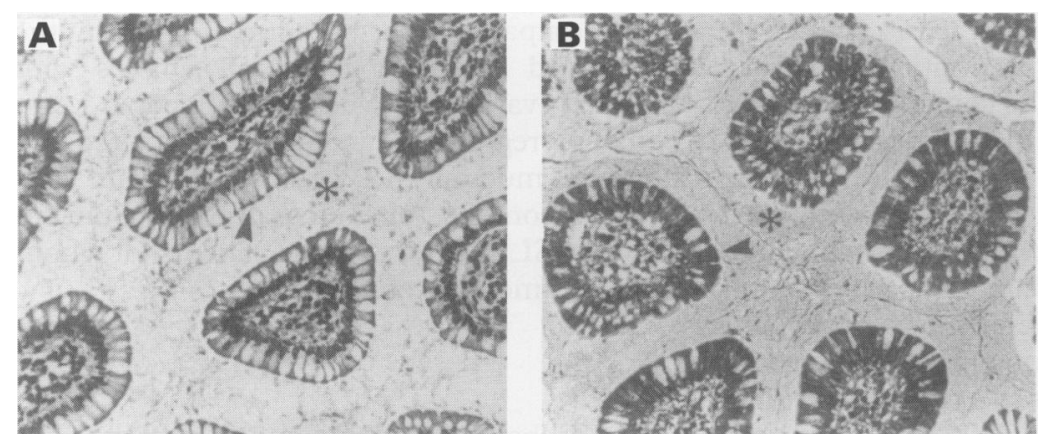

Figure 1: Light micrographs depicting duodenal villous tip cross sections. (A) Shows the non-immune control, with dark nuclei and cytoplasmic outlines with haematoxylin counterstain. The arrow points to an enterocyte with no cytoplasmic immunoreactivity. (B) Demonstrates specific cytoplasmic immunoreactivity (arrow), using antibody to SLP. Note that the brush border membrane, seen as a clear rim luminal to the dark cytoplasmic stain, is not immunoreactive. Note also the positive staining present in the intervillous luminal space (marked by an asterisk; compare with a similar area in Fig 1A). Goblet cells are non-reactive $(A B C$-haematoxylin, original magnification $\times 520)$.

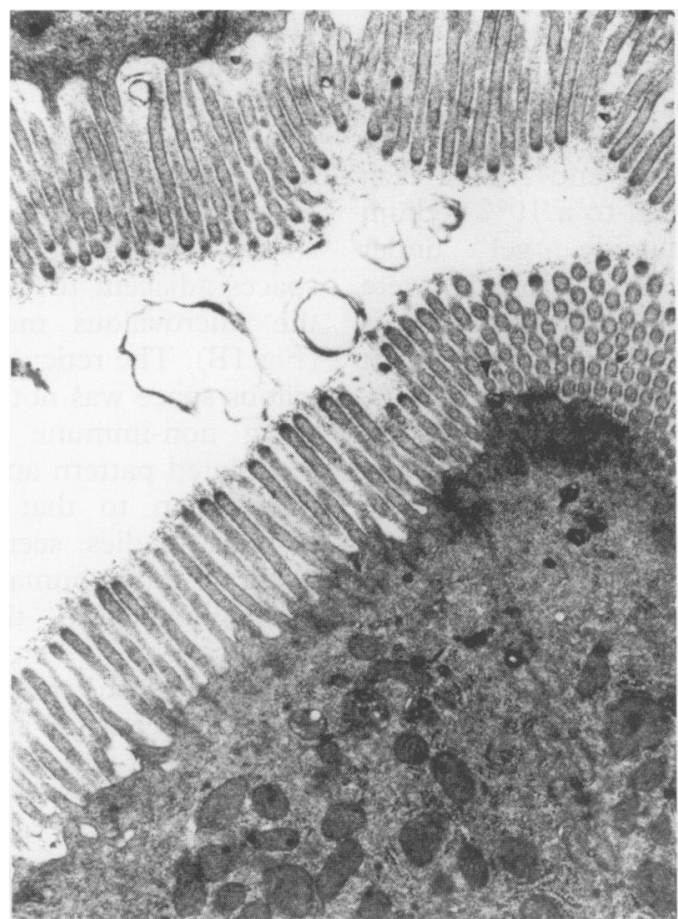

Figure 2: Electron micrograph of enterocytes, highlighting the luminal spaces with unravelling lamellar bodies. Note also the dark-staining intracytoplasmic rounded structures in the apical cytoplasm of both cells. The arrow points to on such structure at the base of a microvillus (tannic acid) osmium tetroxide, original magnification $\times 22000)$. measuring SLP protein content. ${ }^{18}$ Thus, these electron microscopic observations were used as the basis for counting (or scoring) the relative abundance of SLP in the human biopsy specimens.

Table II depicts a significant decrease in the number of SLP in both active duodenal ulcer samples and in samples from patients with gastritis or duodenitis compared with both normal subjects or those with healed duodenal ulcer. Not surprisingly, these differences were not correlated with the $H$ pylori status of the patients, as nearly all patients were antibody positive, including the three patients with healed duodenal ulcer (Table II).

One possible explanation for the lower SLP numbers in patients with active duodenal ulcer
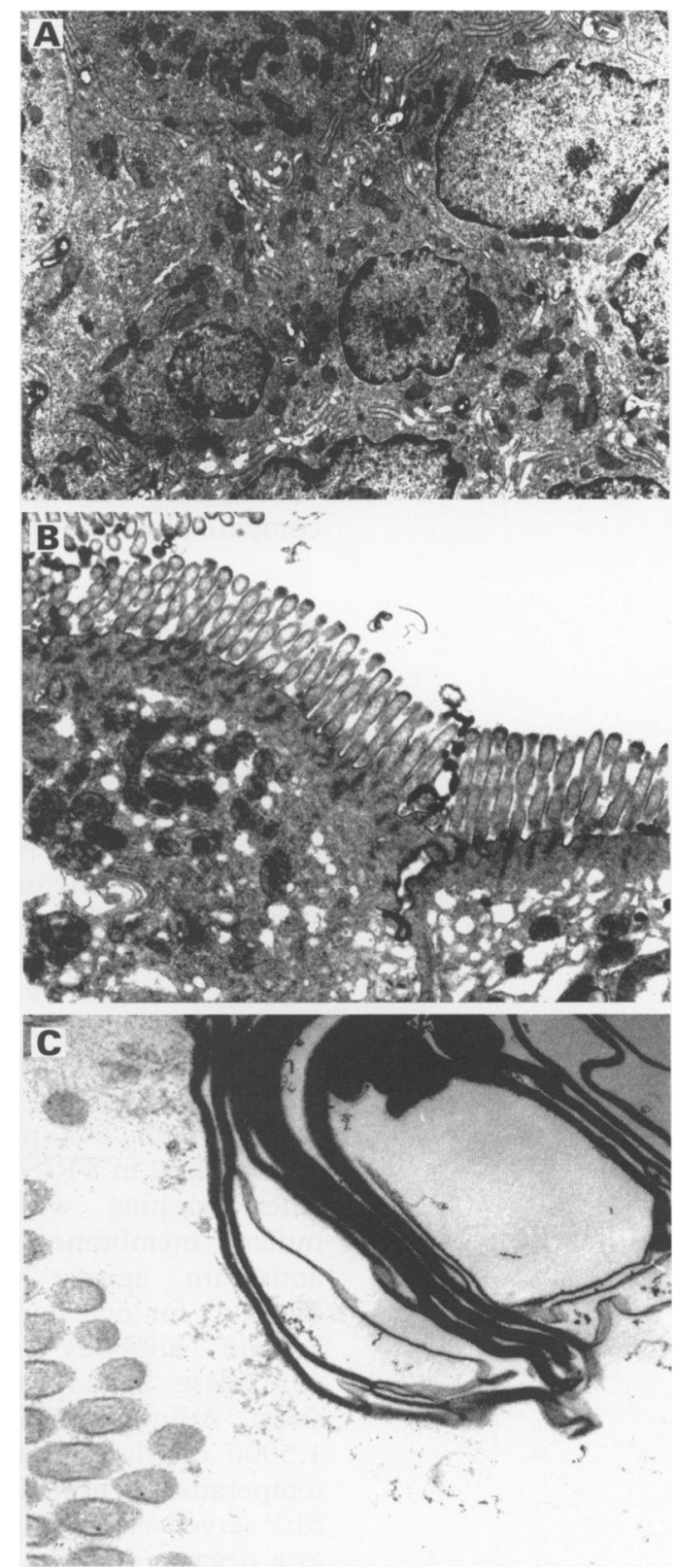

Figure 3: Low power overview electron micrograph of human duodenal mucosal biopsy specimen showing a cross section of enterocytes $(A)$. SLPs are present (two of several noted by arrows) mostly in the paracellular spaces in this case. SLPS are shown in the immediate post-tight junction area $(B)$, as well as over an enterocyte where they appear as unravelling lamellar membranes (C) (tannic acidosmium tetroxide, original magnification $\times 22000$, $\times 22000, \times 65000$ ) 
TABLE II Quantitation of surfactant-like particle content in duodenal biopsy specimens

\begin{tabular}{llll}
\hline Patient group & Number & $\begin{array}{l}\text { Mucosal content } \\
\text { (number/block }\end{array}$ & $\begin{array}{l}\text { H pylori status } \\
\text { (\% ELISA positive) }\end{array}$ \\
\hline Normal controls & 15 & $44(4 \cdot 7)$ & $60(6 / 10)$ \\
Active duodenal ulcer & 13 & $17(3 \cdot 9)^{\star}$ & $91(10 / 11)$ \\
Healed duodenal ulcer & 3 & $67(2 \cdot 2)^{\star} \dagger$ & $100(3 / 3)$ \\
Gastritis/duodenitis & 4 & $9(2 \cdot 7) \ddagger$ & not available \\
\hline
\end{tabular}

Two endoscopic biopsy specimens were taken from the second portion of the duodenum of each subject. They were processed for electron microscopy and particle number was counted as described in Methods. ${ }^{\star}=p<0.01 v$ normal controls; $\dagger=p<0.001 v$ active duodenal ulcer; $\ddagger=\mathrm{p}<0.00005 v$ normal controls by Student's $t$ test. Data shown as mean (SD) unless stated otherwise.

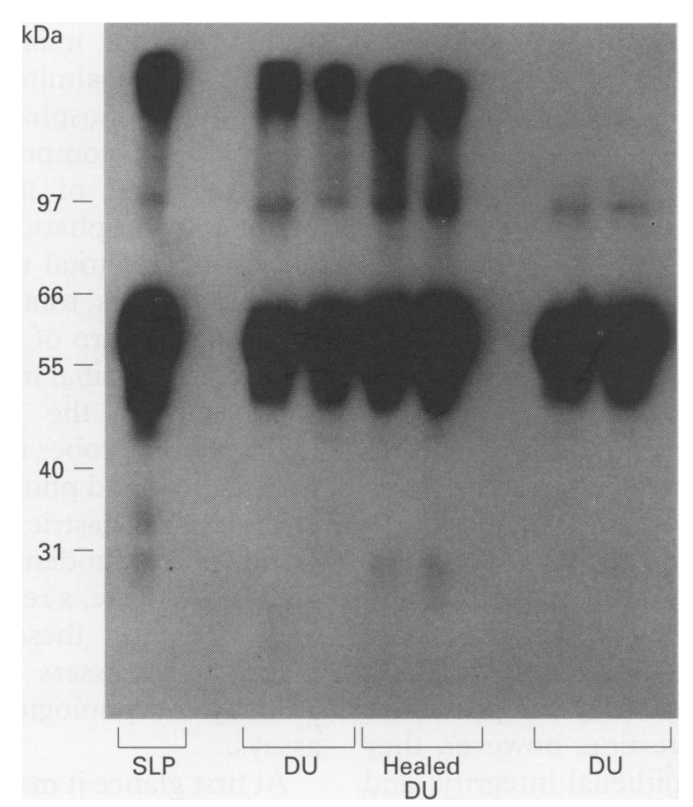

Figure 4: Western blot of SLP proteins in sera from patients with and without peptic ulcer disease. Comparison of sera diluted 1:10 from a patient without peptic ulcer (marked $S L P, 0 \cdot 1 \mu l$ of serum $=7 \cdot 5 \mu \mathrm{g}$ protein applied to each lane) with an equal volume (1 $\mu$ l of sera diluted $1: 10)$ from duodenal ulcer patients. Antiserum raised against human jejunal SLP was used. DU=duodenal ulcer.
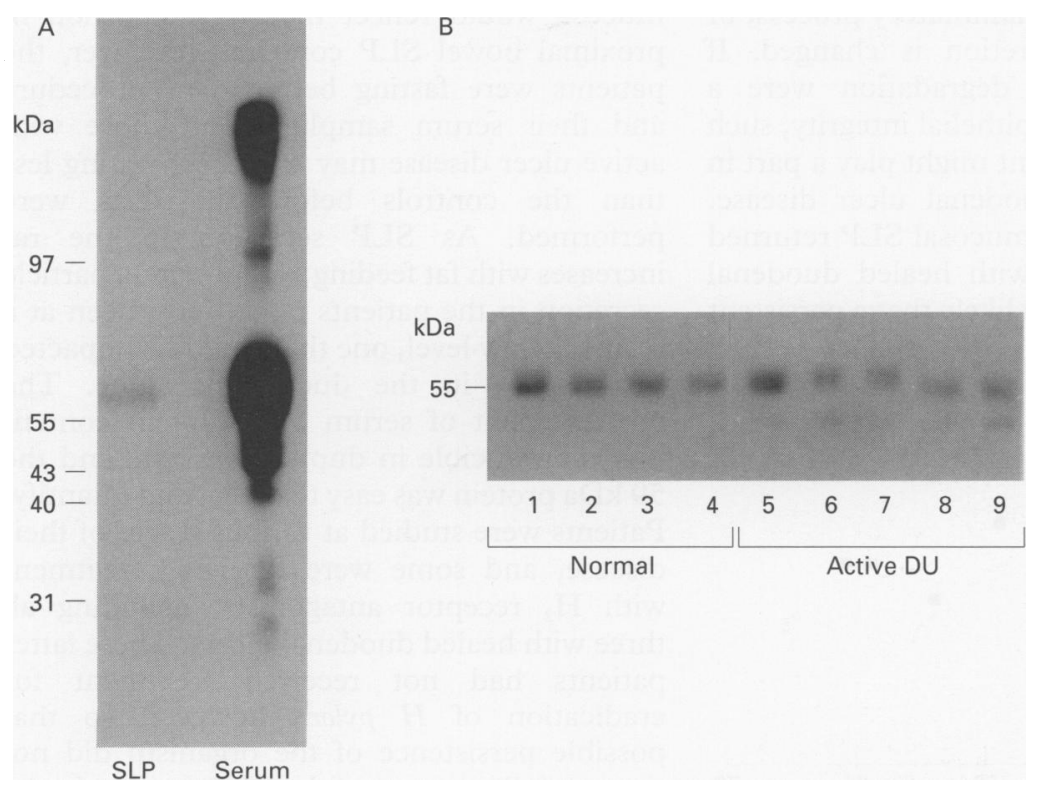

Figure 5: Western blot of SLP proteins in sera from patients with and without peptic ulcer disease. (A) SLP purified from human jejunal mucosal scrapings ${ }^{5}$ was diluted so that the intensity of the $59 \mathrm{kDa}$ band was similar to the diluted serum samples in Figure $5 B$. Its relative migration was similar to a $0.1 \mu \mathrm{l} \mathrm{serum} \mathrm{sample} \mathrm{of} \mathrm{a} \mathrm{control} \mathrm{subject} \mathrm{(noted} \mathrm{as}$ 'serum') and to the more diluted serum samples depicted in Figure 5B. (B) Comparison of the major SLP protein (59 $\mathrm{kDa}$ ) in sera (1 $\mu$ l of 1:100 dilution) from normal (lanes 1-4) and active duodenal ulcer patients (lanes 5-9). This further dilution was used for quantitation by scanning densitometry. disease was decreased production of the particle by the enterocyte. This effect might possibly be determined, at least in part, by the degree of inflammation in the lamina propria. Biopsy specimens from 19 patients were graded for the degree of inflammation and for SLP abundance, using semi-quantitative scores for both analyses. Sixteen patients had specimens with low grade inflammation on morphology, whereas three patients had specimens with high grade inflammation. Biopsy specimens with low grade inflammation had an inflammatory score of $1.3(0.3)$ (mean (SEM)), with an SLP score of $2 \cdot 1(0 \cdot 4)$. Biopsy specimens with high grade inflammation showed an inflammatory score of $2 \cdot 7(0 \cdot 4)$ with an SLP score of $1.9(0.5)$. Thus, the graded inflammatory score did not identify biopsy specimens with high or low SLP abundance. Proteins identified from purified human jejunal and ileal SLP have been identified by protein staining and by western blot, and range in size from 118 to $27 \mathrm{kDa}$, with major proteins of 62 and $52 \mathrm{kDa}^{5}$ In control serum diluted 1:10 many of these bands could be seen (lane 1 marked 'SLP'), although not all bands were detected equally well in all serum samples from ulcer patients (Fig 4). The major immunoreactive bands in the serum were the 59 and $50 \mathrm{kDa}$ bands, corresponding with the major bands found in the control sera (Fig 4). Because the minor bands were not so constant in their immunoreactivity in serum on western blot, the serum was diluted 10-fold more (1:100 final dilution), so that the major band could be reduced to a sharp band that could be easily quantitated by laser densitometry (Fig 5B). There was a decrease in intensity of staining of the $59 \mathrm{kDa}$ SLP protein band in western blots of sera from patients with active duodenal ulcer disease compared with control patients (Figs 4 and 5). Densitometric analysis of the $59 \mathrm{kDa}$ protein confirmed these visual impressions (Table III). Active ulcer patients had $0.26(0.02)$ density units versus 0.40 $(0.02)$ units for control $(p<0.01)$, and the values returned to values even above normal in the patients with healed duodenal ulcer $(0.62$ $(0.04), p<0.007)$. There was a good correlation $(r=0.831$ by least squares analysis) between the mucosal SLP count/block and the serum content of the $59 \mathrm{kDa}$ SLP protein (in density units) derived from individual patient samples (Fig 6). As can be seen, there was no overlap in serum SLP $59 \mathrm{kDa}$ protein content between groups with low or high mucosal SLP counts.

\section{Discussion}

This study of human duodenal mucosa demonstrates osmophilic structures, seen by ultrastructural analysis, which are similar to those found in the rat. As is the case in rat mucosa, the lamellar nature of these structures is difficult to see in fasted samples, ${ }^{18}$ but their lamellar nature can be better appreciated when seen extracellularly. Furthermore, immunocytochemical studies locate the SLP in the apical cytoplasm of villous enterocytes (Fig 
TABLE III Serum content of $59 k D a$ surfactant-like particle (SLP) protein in normal and peptic ulcer patients

\begin{tabular}{llll}
\hline & \multicolumn{3}{l}{ Content of 59 kDa SLP protein in serum } \\
\cline { 2 - 4 } & $\begin{array}{l}\text { Normal } \\
\text { controls }\end{array}$ & $\begin{array}{l}\text { Active duodenal } \\
\text { ulcer } \\
\text { (density units) }\end{array}$ & $\begin{array}{l}\text { Healed } \\
\text { duodenal } \\
\text { ulcer }\end{array}$ \\
\hline & 0.3 & 0.42 & 0.52 \\
& 0.29 & 0.03 & 0.62 \\
& 0.39 & 0.52 & 0.74 \\
& 0.41 & 0.1 & \\
& 0.64 & 0.31 & \\
& 0.39 & 0.23 & \\
& 0.46 & 0.29 & \\
& 0.28 & 0.2 & 0.627 \\
Mean & 0.53 & 0.25 & 0.110 \\
SD & 0.33 & 0.13 & $=0.05$ \\
p $v$ normal & 0.402 & 0.253 & $<0.008$ \\
p $v$ active du & 0.115 & 0.141 & \\
\hline
\end{tabular}

Sera from 17 patients in these three groups were available. Active peptic ulcer disease included three patients with gastritis/duodenitis and eight with ulcer. The $59 \mathrm{kDa}$ SLP protein was identified on western blots (Fig 3) and the bands scanned, quantitated in arbitrary density units. The average of duplicate samples are recorded, and comparisons made by two tailed Student's $t$ test.

1)..$^{2-4}$ These morphological findings confirm the earlier report that apical scrapings from human small intestine contain structures with properties very similar to rat SLP. ${ }^{5}$ The parts that these particles may play in health and disease and in the various portions of the gastrointestinal tract are as yet undefined. In the stomach they may play a protective part. ${ }^{13}{ }^{15}$ In the small intestine, however, they may reflect functional epithelial integrity, and may play a part as yet incompletely delineated in absorptive processes. Indeed, the appearance of intra and extracellular lamellar bodies increased after fat feeding in the rat, and correlated with mucosal content of SLP proteins measured by ELISA. ${ }^{18}$

The decrease in SLP in active duodenal ulcer or duodenitis suggests either that the SLP are consumed by the inflammatory process, or that SLP synthesis/secretion is changed. If modified synthesis or degradation were a functional correlate of epithelial integrity, such a decrease in SLP content might play a part in the pathogenesis of duodenal ulcer disease. Because the content of mucosal SLP returned to normal in patients with healed duodenal ulcers, it seems to be less likely that a persistent

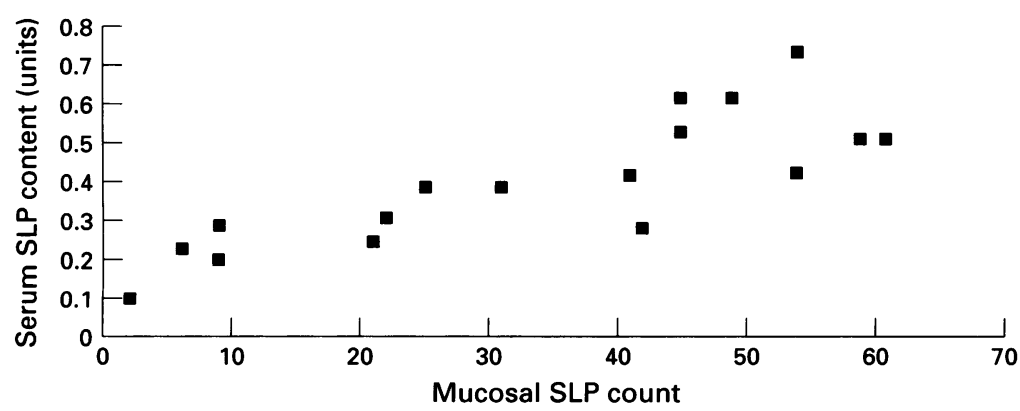

Figure 6: Correlation between mucosal SLP count/block and serum SLP content in normal and peptic ulcer disease patients. The serum values from Table III were paired with the mucosal SLP counts from the same patients. By least squares analysis the regression coefficient $\mathrm{r}$ was 0.831 . The SLP content of serum refers to the densitometric reading in arbitary units of $0.1 \mu \mathrm{l}$ of serum. The SLP count of the mucosal refers to the number of particles seen per block. decrease in mucosal SLP content might contribute to the cause of the disease. Recent evidence has suggested that phospholipids are important in creating a water impermeable layer for the human gastric mucosa. ${ }^{13-17}$ Moreover, the hydrophobic lining of the stomach seems to be maintained separately from the mucous gel layer. ${ }^{28}$ The most prominent phospholipids recovered from the apical surface layer of gastrointestinal tissue have been phosphatidylcholine and phosphatidylethanolamine, ${ }^{1329}$ and it has been proposed that the most active phospholipid component for maintaining the hydrophobic surface is dipalmitoyl-phosphatidylcholine. ${ }^{13}$ Dipalmitoyl-phosphatidylcholine is the major phospholipid component of both pulmonary surfactant and of the intestinal SLP. ${ }^{1-4} \mathrm{Di}-$ palmitoyl-phosphatidylcholine accounts for only $2-6 \%$ of total apical scrapings of gastric mucosa. ${ }^{28}$ Thus, total phospholipid may not be the best measure of the function of either the gastric or intestinal mucosa. This conclusion is supported by the finding that fluorescent hydrophobic probes that detect the presence of neutral lipid and phospholipid identify mucous cells in the gastric mucosa and Brunner's glands of the duodenum, but fail to identify the villus enterocyte, a reported source of intestinal SLP. ${ }^{4}{ }^{30}$ For these reasons we chose to identify and assess the duodenal enterocyte SLP by morphological and protein detection assays.

At first glance it may seem surprising that the serum level of small bowel SLP protein(s) correlated with the mucosal content of the particles in the duodenum, representing only a small portion of the proximal small intestine. In the rat the particle is more abundant in proximal mucosa, especially the duodenum. ${ }^{3}$ It is possible that the same distribution is present in humans, and that sampling duodenal mucosa would reflect the largest portion of proximal bowel SLP content. Moreover, the patients were fasting before their procedure and their serum sampling, and those with active ulcer disease may have been eating less than the controls before the tests were performed. As SLP secretion in the rat increases with fat feeding, ${ }^{18} 19$ proximal particle secretion in the patients might have been at a relatively low level, one that could be impacted by changes in the duodenum alone. The measurement of serum SLP protein content was reproducible in duplicate assays, and the $59 \mathrm{kDa}$ protein was easy to detect and quantify. Patients were studied at various stages of their disease, and some were receiving treatment with $\mathrm{H}_{2}$ receptor antagonists, including all three with healed duodenal ulcers. These latter patients had not received treatment for eradication of $H$ pylori, however, so that possible persistence of the organism did not prevent full recovery of the SLP content in the duodenum. Thus, it seems unlikely that the loss of duodenal SLP in active duodenal ulcer disease is a direct result of $H$ pylori infection of the duodenum in areas of gastric metaplasia. In the stomach a close relation has been reported between $H$ pylori and mucosal phospholipids, ${ }^{32}$ 
with significant decreases in phosphatidylcholine and phosphatidylethanolamine and total phospholipid concentrations during infection. Moreover, fragmented phospholipid structures were seen surrounding $H$ pylori organisms. ${ }^{32}$ Although $H$ pylori is the most important factor in recurrence of duodenal ulcer disease, it is exclusively associated with gastric type tissue, possibly related to differences in the secreted phospholipid structures produced by the gastric and duodenal cells. In the duodenum the enterocyte is the major site of SLP production, and duodenal SLP has not been reported to be associated with $H$ pylori. This may explain why the $H$ pylori status of the patients did not correlate with SLP content of their tissue or serum.

The finding of SLP within the paracellular space confirms the same localisation in suckling ${ }^{33}$ and adult ${ }^{36}$ rat intestinal mucosa. Moreover, in the rat mucosa ${ }^{63}$ and in cultures of fetal enterocyte-like (Caco-2) cells, $^{34}$ particles are localised to the apical space especially over tight junctions. When permeability of tight junctions was increased in cultures of Caco-2 cells, the appearance of particles in apical medium was increased, ${ }^{34}$ consistent with the concept that SLP can be secreted initally into the basolateral space and then transported to the intestinal lumen through the tight junctions. This bi-directional secretion can account for the good correlation seen between the serum protein content of SLP proteins and the electron microscopic identification of particles in intestinal mucosa.

This work was supported in part by grant DK-14038 from the National Institutes of Health (NIDDK), and by a grant from the Hebrew University and Hadassah.

1 Stratton CJ. In: Robertson B, Van Golde, IMG, eds. Pulmonary surfactant. Amsterdam: Elsevier, 1984: 68-118.

2 Hills BA, Butler BD, Lichtenberger LM. Gastric mucosal barrier: hydrophobic lining to the lumen of the stomach. Am ₹ Physiol 1983; 244 (Gastrointest Liver Physiol 7): G561-8.

3 DeSchryver-Kecskemeti K, Eliakim R, Carroll S, Stenson WF, Moxley MA, Alpers DH. Intestinal surfactant-like material. A novel secretory product of the rat enterocyte. material. A novel secretory product

4 Eliakim R, DeSchryver-Kecskemeti K, Nogee L, Stenson WF, Alpers DH. Isolation and characterization of small intestinal surfactant-like particle containing alkaline phosphatase and other digestive enzymes. $\mathcal{F}$ Biol Chem 1989; 264: 20614-9.

5 Mahmood A, Mahmood S, DeSchryver-Kecskemeti K, Alpers DH. Characterization of protein in rat and human intestinal surfactant-like particles. Arch Biochem Biophys 1993; 300: 280-6.

6 DeSchryver-Kecskemeti K, Eliakim R, Green K, Alpers $\mathrm{DH}$. A novel intracellular pathway for rat intestinal digestive enzymes (alkaline phosphatase and sucrase) via a lamellar particle. Lab Invest 1991; 65: 365-73.

7 Kao Y-CJ, Lichtenberger LM. A method to preserve extracellular surfactant-like phospholipids on the surface of rodent gastric mucosa. $\mathcal{F}$ Histochem Cytochem 1990; 38: 2122-31.

8 Hills BA. A physical identity for the gastric mucosal barrier. Med F Austr 1990; 153: 76-81.

9 Hills BA, ed. The Biology of surfactant. Cambridge: University Press, 1988.
10 Rees S. Membranous neuronal and neuroglia inclusions produced by intracerebral injection of suramin. $\mathcal{F}$ Neurol Sci 1978; 36: 97-109.

11 Gil J. Histological preservation and ultrastructure of alveolar surfactant. Annu Rev Physiol 1985; 47: 753-63.

12 Eliakim R, Goetz G, Shao J-S, Alpers DH. Surfactant-like particles (SLP) isolated from rat and human colon are distinct from the microvillus membrane (MVM) and from small intestinal SLP. Gastroenterology 1995; 108: A283.

13 Butler BD, Lichtenberger LM, Hills BA. Distribution of surfactants in the canine gastrointestinal tract and their ability to lubricate. Am $\mathcal{F}$ Physiol 1983; 244 (Gastrointest Liver Physiol 7): G645-1.

14 Sarosiek J, Slomiany A, Takagi A, Slomiany BL. Hydrogen ion diffusion in dog gastric mucus glycoprotein: effect of ion diffusion in dog gastric mucus glycoprotein: effect of Biochem Biophys Res Commun 1984; 118: 523-31.

15 Lichtenberger LM, Graziani LA, Dial EJ, Butler BD, Hills BA. Role of surfactant-active phospholipids in gastric cytoprotection. Science 1983; 219: 1327-9.

16 Hills BA. Water repellency induced by pulmonary surfactants. F Physiol (Lond) 1982; 325: 175-86.

17 Hills BA. Gastric mucosal barrier: stabilization of hydrophobic lining to the stomach by mucus. Am $\mathcal{F}$ Physiol 1985; 249 (Gastrointest. Liver Physiol 12): 1985; G342-G345.

18 Mahmood A, Yamagishi F, Eliakim R, DeSchryverKecskemeti K, Gramlich TL, Alpers DH. A possible role for rat intestinal surfactant-like particles in transepithelial triacylglycerol transport. $\mathcal{F}$ Clin Invest 1994; 93: 70-80.

19 Yamagishi F, Komoda T, Alpers DH. Secretion and distribution of rat intestinal surfactant-like particles following fat feeding. Am F Physiol 1994; 266 (Gastrointest Liver Physiol 29): G944-52.

20 Orchard JL, Bickerstaff CA. Gastric mucosal phospholipid concentrations in human patients with gastritis, gastric ulcer and normals. Gastroenterology 1986; 90: A1573.

21 Nardone G, Laccetti P, Civiletti C, Budillon G. Phospholipid composition of human gastric mucosa: a study of endoscopic biopsy specimens. Gut 1993; 34: 456-60.

22 Anderson JT, Murray FE, Gallacher C, Ross PE, Milne G, Hopwood D. Novel surfactant-like lipid (SLL) of human stomach, duodenum, and rectum. Gut 1993; 34 (Suppl. 4): $\$ 16$

23 Fich A, Carel RS, Keret D, and Goldin E. Seroprevalence of helicobacter pylori in the Israeli population. Eur $\mathcal{F}$ Gastroenterol Hepatol 1993; 55: 339-41.

24 Hsu S-M, Raine L, Fanger $H$. Use of avidin-biotinperoxidase complex (ABC) in immunoperoxidase techniques: a comparison between $\mathrm{ABC}$ and unlabeled antibody (PAP) procedures. F Histochem Cytochem 1981; 29: 577-80.

25 Kalina $M$, Pease DC. The preservation of ultrastructure in saturated phosphatidyl cholines by tannic acid in model systems and type II pneumocytes. $\mathcal{f}$ Cell Biol 1977; 74: systems

26 Weibel ER. Stereological principles for morphometry in electron microscopic cytology. Int Rev Cytol 1969; 26: 235-302.

27 Crang RFE, Klomparens KL. Artifacts in biological electron microscopy. New York: Plenum, 1988.

28 Goddard PJ, Kao Y-CJ, Lichtenberger LM. Luminal surface hydrophobicity of canine gastric mucosa is dependent on a surface mucous gel. Gastroenterology 1990; 98: 361-70.

29 Schmitz MGJ, Renooij W. Phospholipids from rat, human, and canine gastric mucosa. Gastroenterology 1990; 99: and can

30 Tietze CC, Bechich MJ, Engle M, Stenson WF, Eliakim R, Alpers DH. Caco-2 cell transfection by rat intestinal alkaline phosphatase cDNA increases surfactant-like particles. Am $\mathscr{f}$ Physiol 1992; 263 (Gastrointest Liver Physiol 26): G756-66.

31 Yamagishi F, Komoda T, Alpers DH. Secretion and distribution of rat intestinal surfactant-like particles following fat feeding. Am f Physiol 1994; 266 (Gastrointest Liver Physiol 29); G944-52.

32 Nardone G, D'Armiento F, Corso G, Coscione P, Esposito M, Budillon G. Lipids of human gastric mucosa: Effect of Helicobacter pylori infection and nonalcoholic cirrhosis. of Helicobacter pylori infection and

33 Eliakim R, Becich MJ, Green K, Alpers DH. Developmental expression of intestinal surfactant-like particles in rats. Am F Physiol 1991; 261 (Gastrointest Liver Physiol 24): G269-79.

34 Engle MJ, Grove ML, Becich MJ, Mahmood A, Alpers DH Appearance of surfactant-like particles in apical medium of Caco-2 cells may occur via tight junctions. Am $\mathcal{F}$ Physiol 1995; 268 (Cell Physiol 37): C1401-13. 